\title{
Simulation model of 3-phase PWM rectifier by using MATLAB/Simulink
}

\author{
Salam Waley Shneen, Ghada Adel Aziz \\ University of Technology, Iraq, Baghdad
}

\begin{tabular}{l}
\hline \hline Article Info \\
\hline Article history: \\
Received Oct 5, 2020 \\
Revised Mar 26, 2021 \\
Accepted Apr 10, 2021 \\
\hline
\end{tabular}

\section{Keywords:}

3-phase rectifier (AC/DC)

FWR

HWR

Power electronic devices

PWM

\begin{abstract}
Many industrial applications require the use of power electronic devices, which in turn help in overcoming the problems of variable load and fluctuations that occur at the end of feeding. The current study emphasizes that the use of different electric power generation systems with industrial applications needs control devices to work on improving the power quality and performance of systems in which there is an imbalance in the voltage or current due to the change of loads or feeding from the source. The present study also presents a model of a transformer widely used in industrial applications and this work includes simulating a three-phase rectifier by MATLAB. There are four cases in this work HWR (uncontrolled and controlled) and FWR (uncontrolled and uncontrolled) with different loads (R, $\mathrm{RL} \& \mathrm{RC}$ ) including full wave type AC/DC using six electronic transformer silicon control rectifier (SCRs) once as well as unified half wave using three electronic transformer silicon control rectifier (SCRs). Simulation results include input, output voltage, and current with the waveform.
\end{abstract}

This is an open access article under the CC BY-SA license.

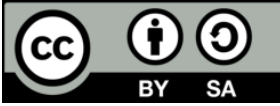

\section{Corresponding Author:}

Salam Waley Shneen

Energy and Renewable Energies Technology Center

University of Technology, Iraq-Baghdad

52 Industry street, Baghdad, Iraq

Email: salam_waley73@yahoo.com

\section{INTRODUCTION}

Power electronic devices (PED), it had incorporate rectifier (AC_DC), inverter (DC_AC), converter (DC_DC and AC_AC) [1]-[5]. The kind of AC_DC is one of PED that use to convert the ac voltage source to dc voltage that use to the load [6]-[8]. The rectifier utilized when the heap is DC and the source was AC [9][11]. There are numerous applications in industrial like battery chargers, HVDC and Elevator and so forth [12]-[14]. There are numerous kinds of rectifier with natural switch. The commonplace switch model incorporate single-stage uncontrolled, three-stage uncontrolled, three-stage controlled and single-stage controlled. These switches required gadget type nonlinear for models thyristors like (SCR, GOT \& TRIAC), transistors like (IGBT) and diodes. The switch type uncontrolled like diode had no control like low power and high force. The quantity of switches in rectifier framework was one or four at utilizing single stage yet it was three or six at utilizing three stage [15]-[17]. Single stage incorporate HWR and FWR. The HWR had source and one switch at utilizing single stage or three switches at three stage. The FWR had source and four switches at utilizing single stage or six switches at three stage. Uncontrolled rectifier, there are utilizing diodes that had no control. Controlled rectifier, there are utilizing various switches like MOSFET, IGBT, TRIAC and so forth [18]-[20]. In this study, right now mimicked numerous sorts for rectifier, 3-phase rectifier uncontrolled (HWR and FWR) and 3-phase rectifier controlled (HWR) and FWR. Moreover, this survey had reproduced the diverse load(R, R_C and R_L). 


\section{MATHEMATICAL MODEL OF 3-PHASE RECTIFIER}

Current simulations include a 3-phase rectifier with a half-mix, as well as a full-wave rectifier [21]-[24]. The work in both cases had divided into the use of two types of electronic power devices, one without control and the other with control. The mathematical model includes many terms that represent the specifications of the ingredient and it is worth noting that it has used to represent the ingredient mathematically from the crescent moon of mathematical equations. It included, root mean square values (Vrms \& Irms), average values (Vavg \& Iavg), input source power (Pac), output power (Pdc), efficiency ( $\eta$ ), ripple factor $(\mathrm{RF})$, form factor $(\mathrm{FF})$, harmonic factor $(\mathrm{HF})$, crest factor $(\mathrm{CF})$, and power factor $(\mathrm{PF})[25]$.

$$
\begin{aligned}
& V_{r m s}=\left\{\frac{1}{T} \int_{0}^{T} V^{2}(t) d t\right\}^{0.5} \\
& I_{r m s}=\left\{\frac{1}{T} \int_{0}^{T} I^{2}(t) d t\right\}^{0.5} \\
& V_{a v g}=\frac{1}{T} \int_{0}^{T} V(t) d t \\
& I_{a v g}=\frac{1}{T} \int_{0}^{T} I(t) d t \\
& P_{a c}=V_{r m s} \cdot I_{r m s} \\
& P_{d c}=V_{a v g} \cdot I_{a v g} \\
& \eta=\frac{P_{a c}}{P_{d c}}=\frac{V_{r m s} \cdot I_{r m s}}{V_{a v g} I_{a v g}} \\
& \mathrm{RF}=\frac{V_{a c}}{V_{d c}} \\
& \mathrm{PF}=\frac{V_{r m s}}{V_{a v g}} \\
& \mathrm{HF}=\left[\left(I_{s 1} / I_{s}\right)^{2}-1\right]^{0.5} / I_{s} \cos \emptyset \\
& I_{s}
\end{aligned}
$$

In addition, there are three waveforms of three phase as (13), (14), (15):

$$
\begin{aligned}
& V_{1}=V_{m} \times \sin \omega t \\
& V_{2}=V_{m} \times \sin \left(\omega t-120^{\circ}\right) \\
& V_{3}=V_{m} \times \sin \left(\omega t+120^{\circ}\right)
\end{aligned}
$$

\section{SIMULATION MODEL OF 3-PHASE RECTIFIER}

Simulation model of 3-phase rectifier, in this section the review had uncontrolled 3-phase rectifier for HWR, uncontrolled 3-phase rectifier for FWR, controlled 3-phase rectifier for HWR, controlled 3-phase rectifier for FWR system with different load at R, R_L \& R_C. The simulation model of uncontrolled 3-phase rectifier for HWR as shown in Figures 1 to 3, the simulation model of uncontrolled 3-phase rectifier for FWR as shown in Figures 4 to 6, the simulation model of controlled 3-phase rectifier for HWR as shown in Figures 7 to 9 and the simulation model of controlled 3-phase rectifier for FWR as shown in Figure 10, Figure 11 and Figure 12. 


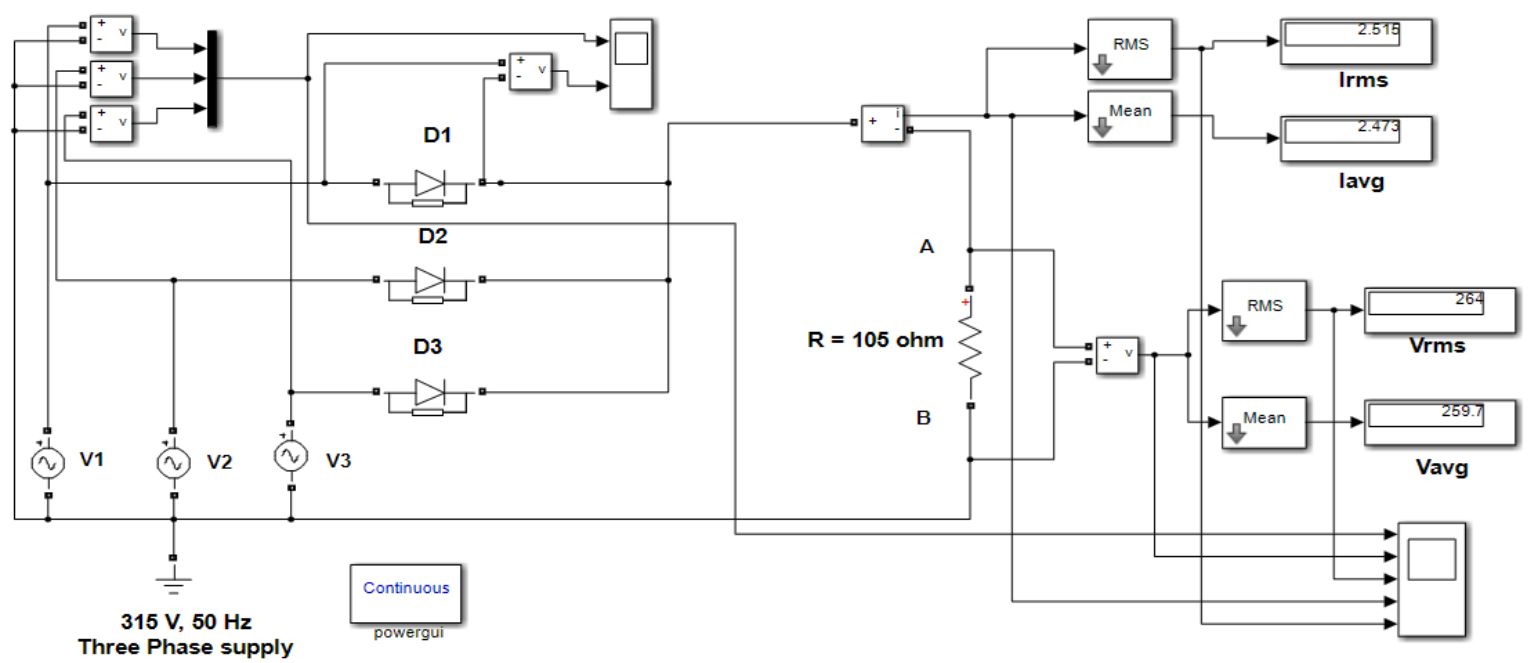

Figure 1. The simulation model of uncontrolled for HWR at load (R)

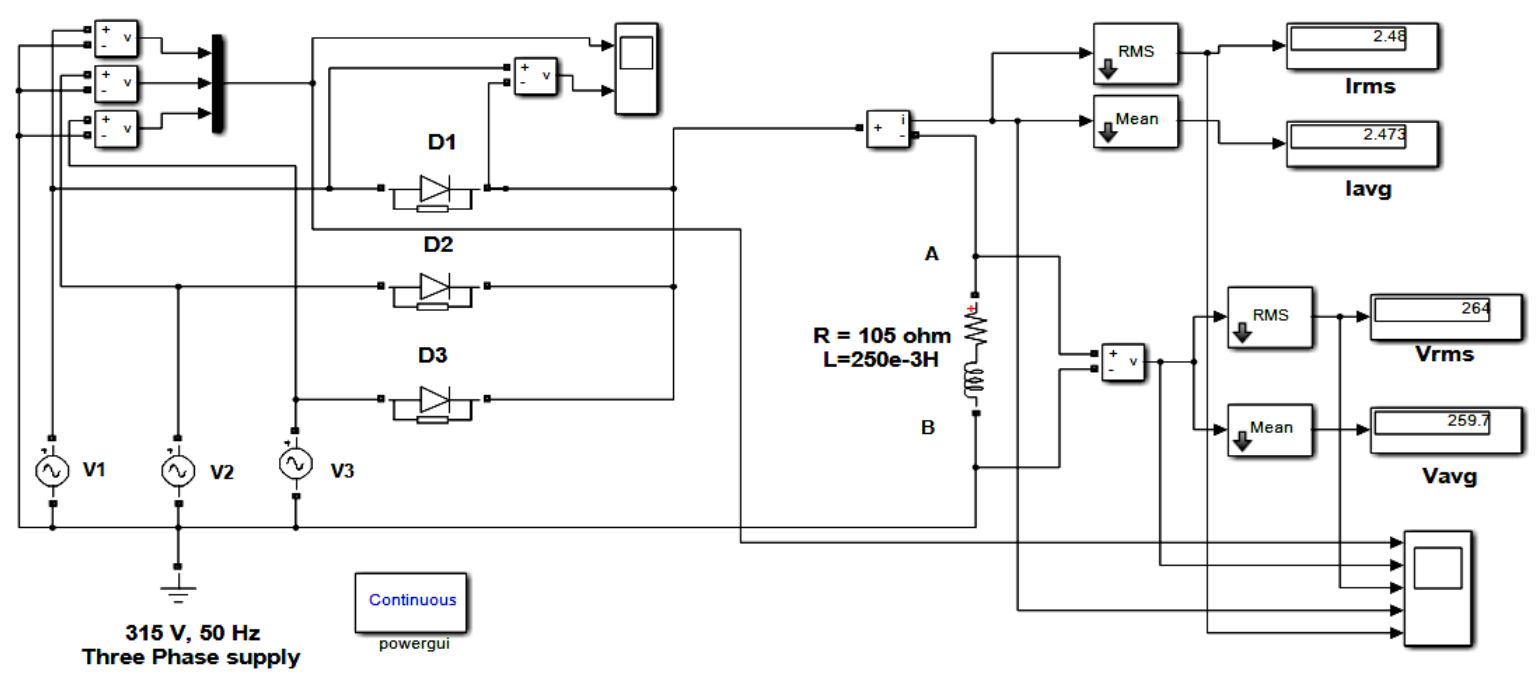

Figure 2. The simulation model of uncontrolled for HWR at load (R-L)

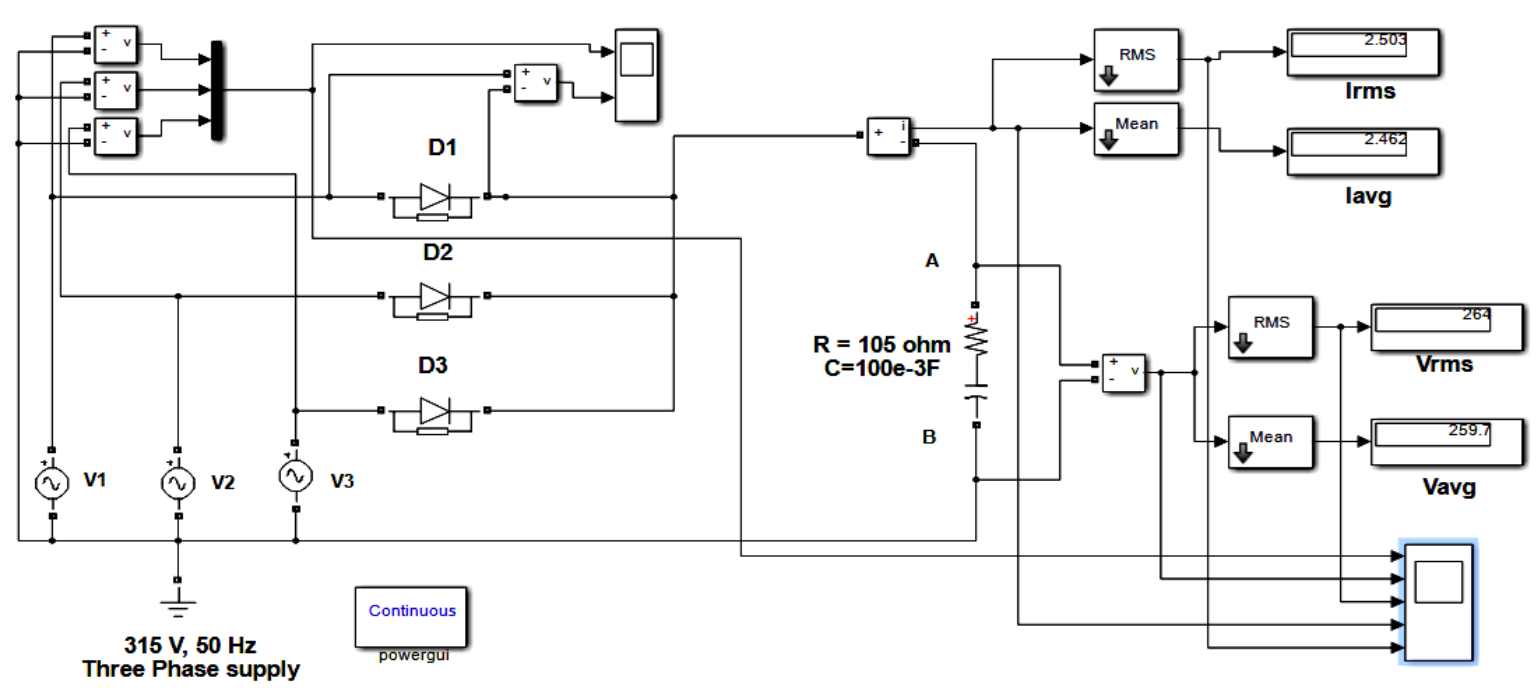

Figure 3. The simulation model of uncontrolled for HWR at load (R-C) 


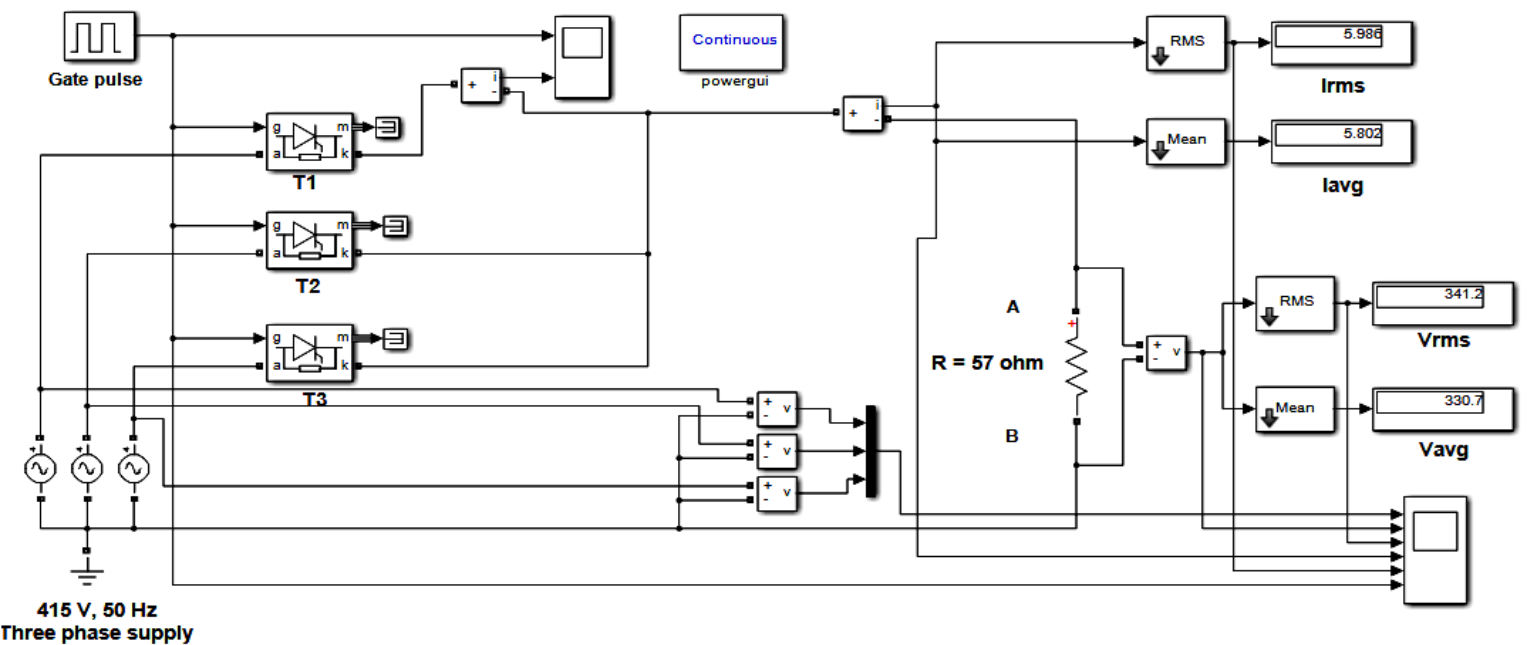

Figure 4. The simulation model of controlled for HWR at load (R)

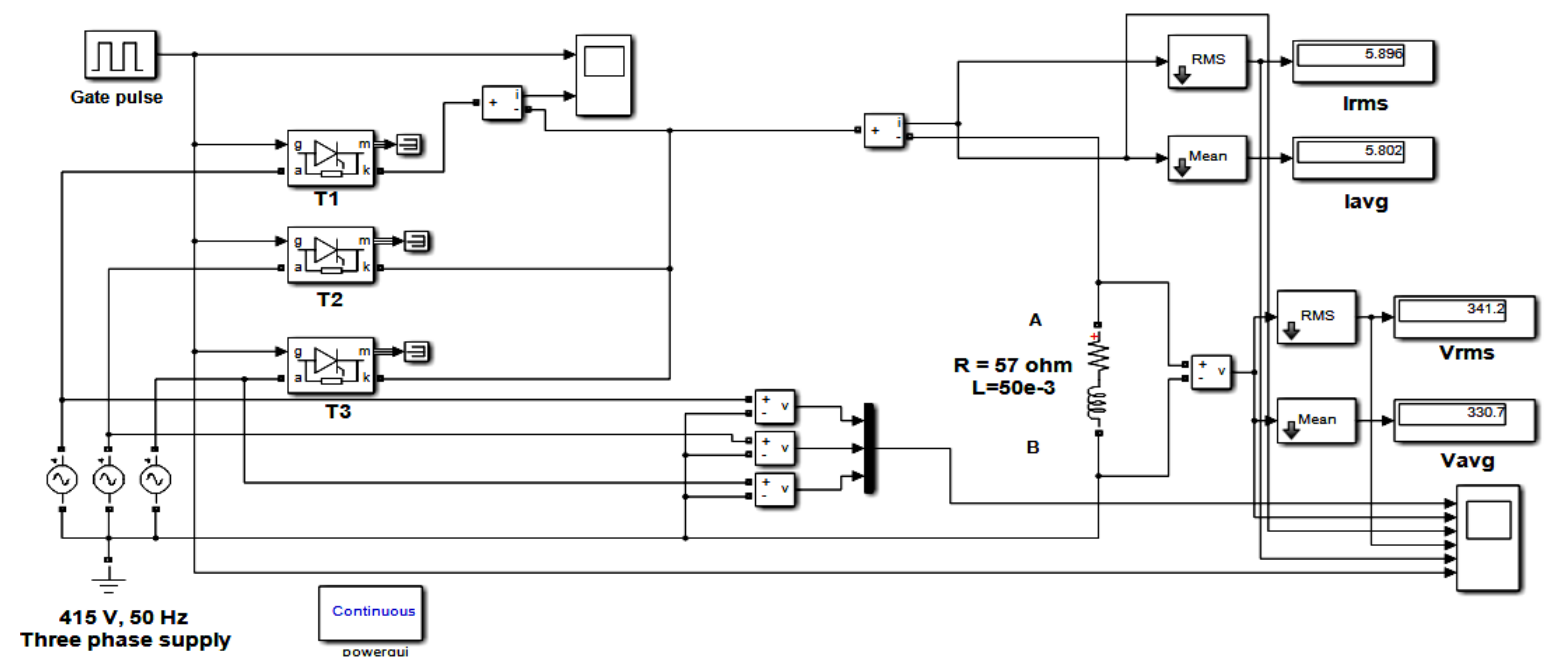

Figure 5. The simulation model of controlled for HWR at load (R-L)

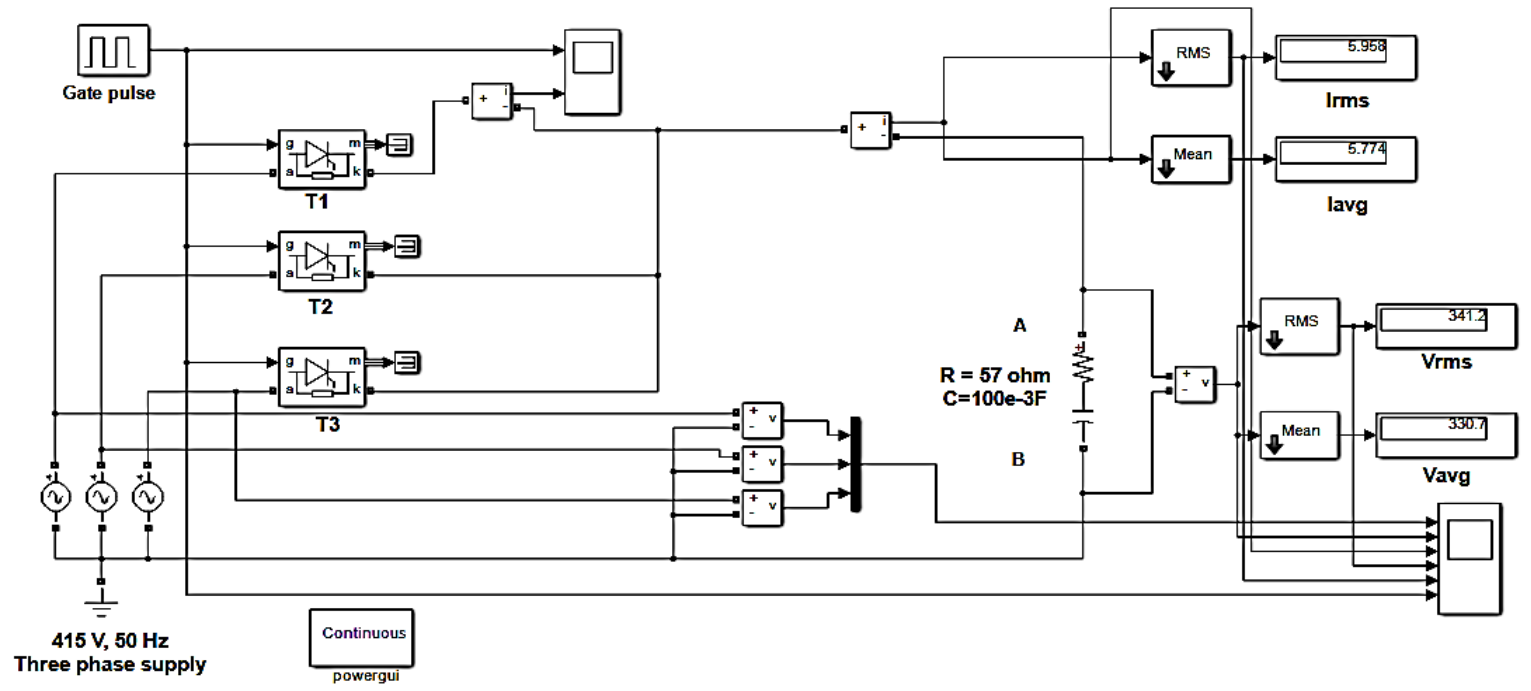

Figure 6. The simulation model of controlled for HWR at load (R-C) 


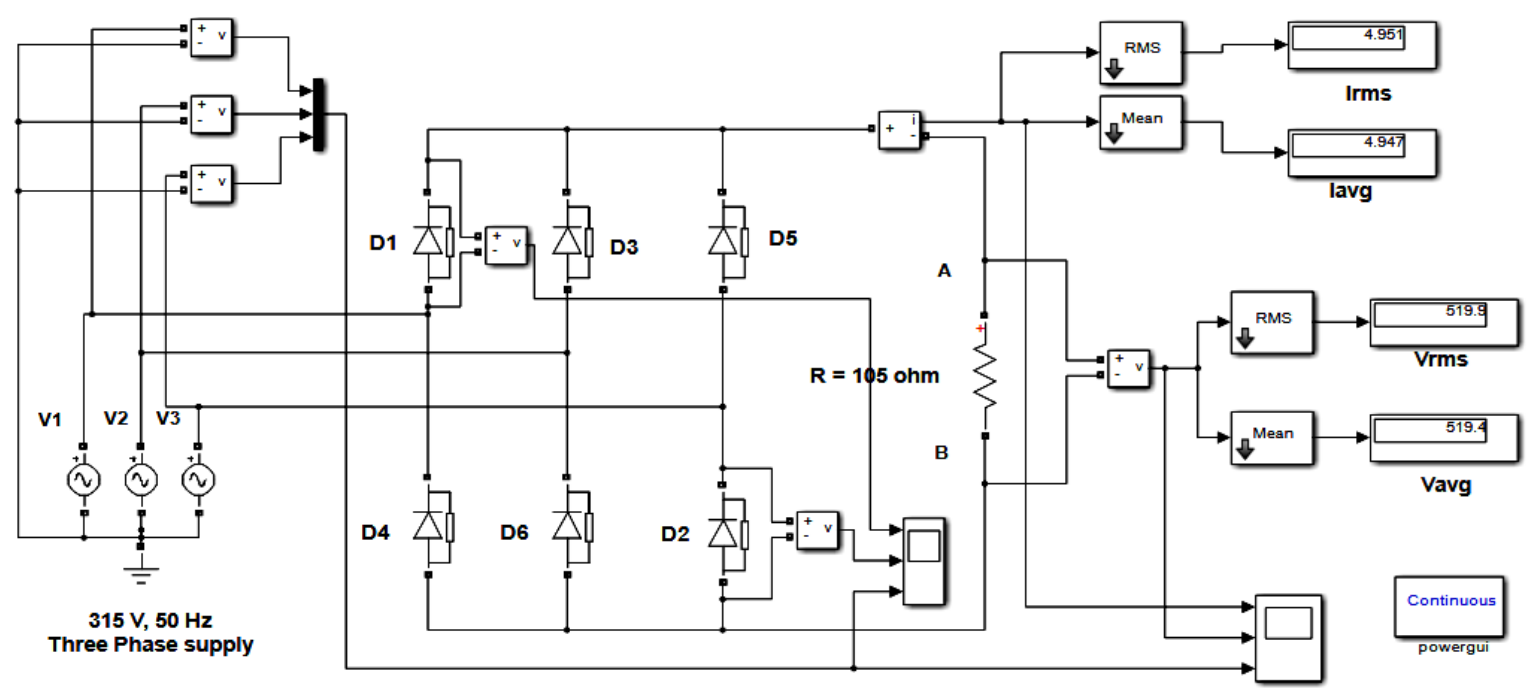

Figure 7. The simulation model of uncontrolled for FWR at load (R)

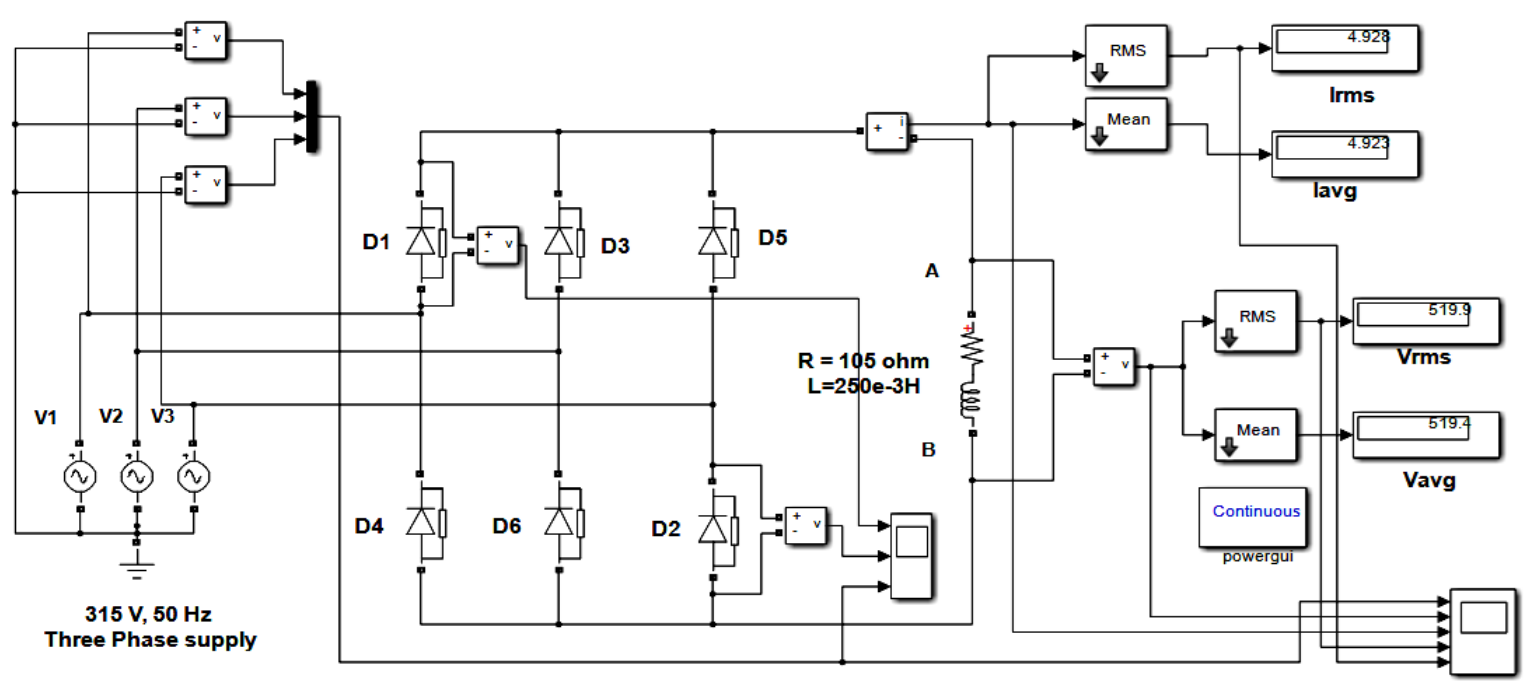

Figure 8. The simulation model of uncontrolled for FWR at load (R-L)

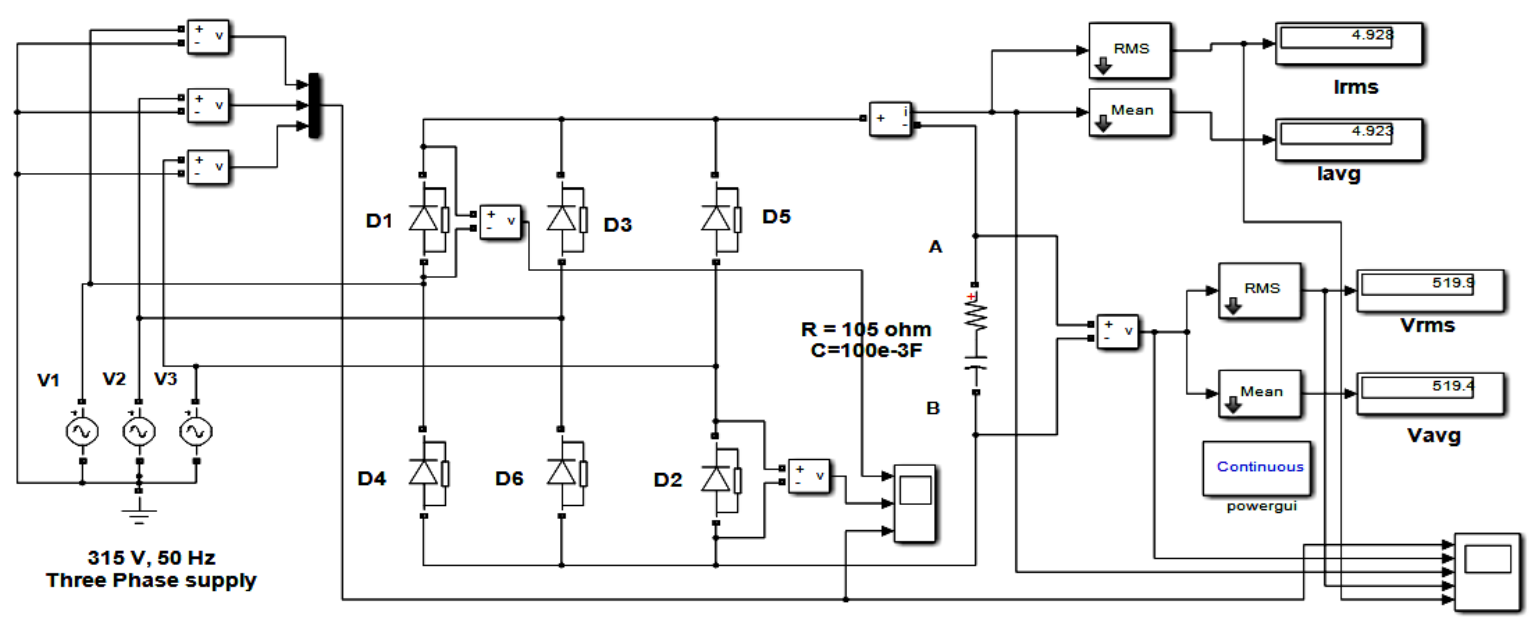

Figure 9. The simulation model of uncontrolled for FWR at load (R-C) 


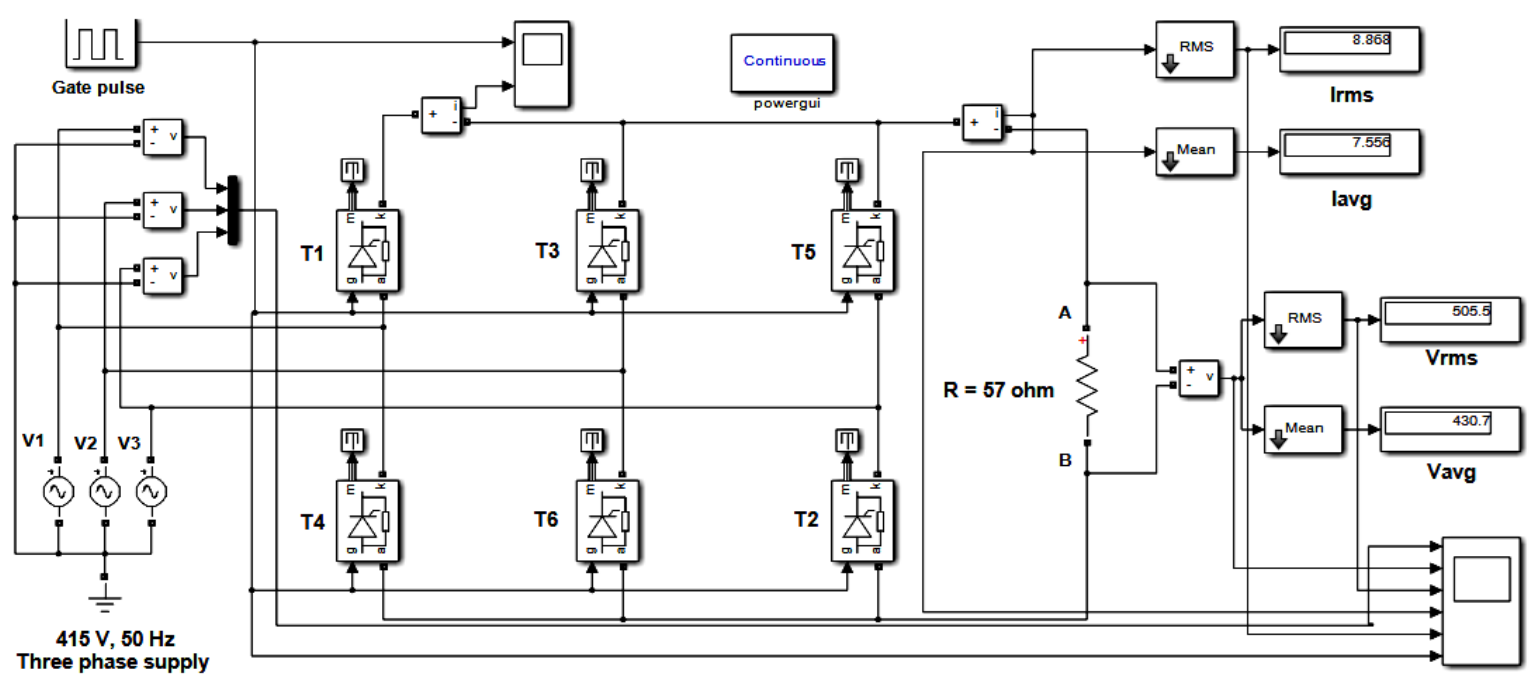

Figure 10. The simulation model of controlled for FWR at load (R)

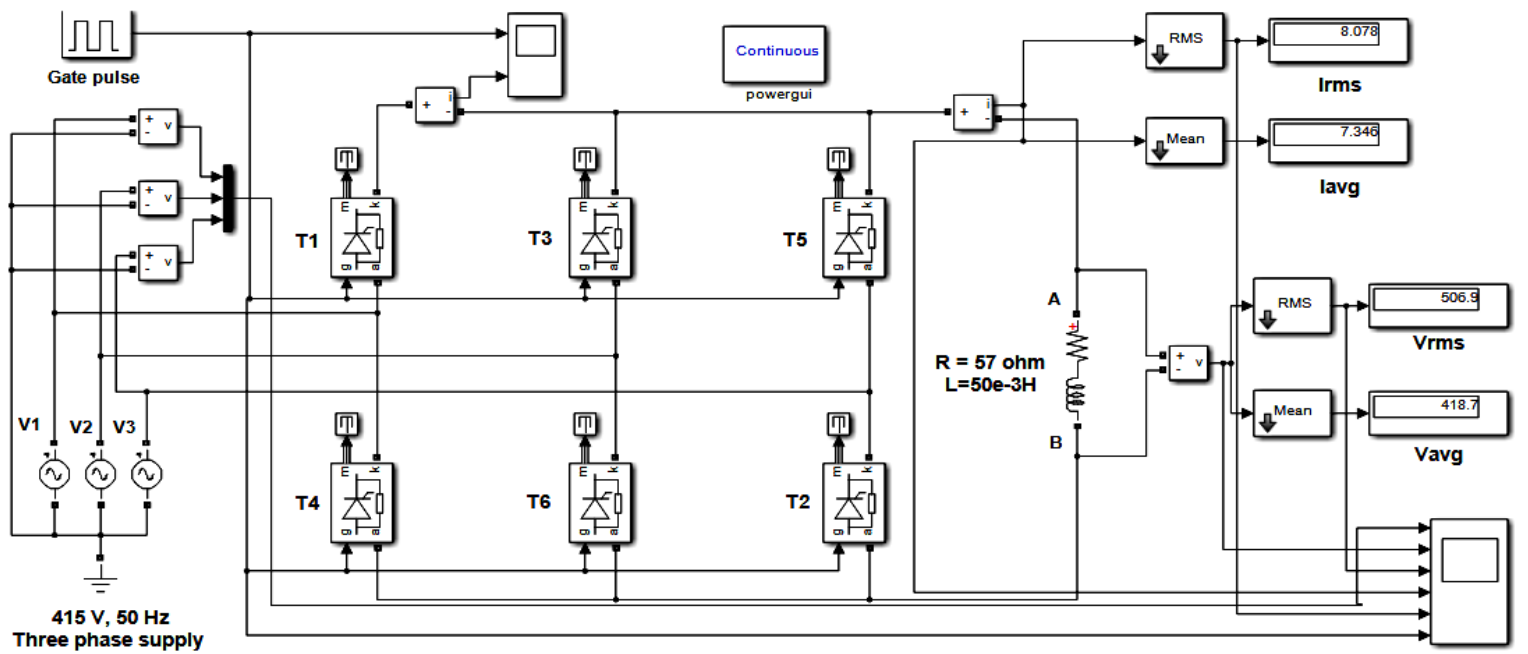

Figure 11. The simulation model of controlled for FWR at load (R-L)

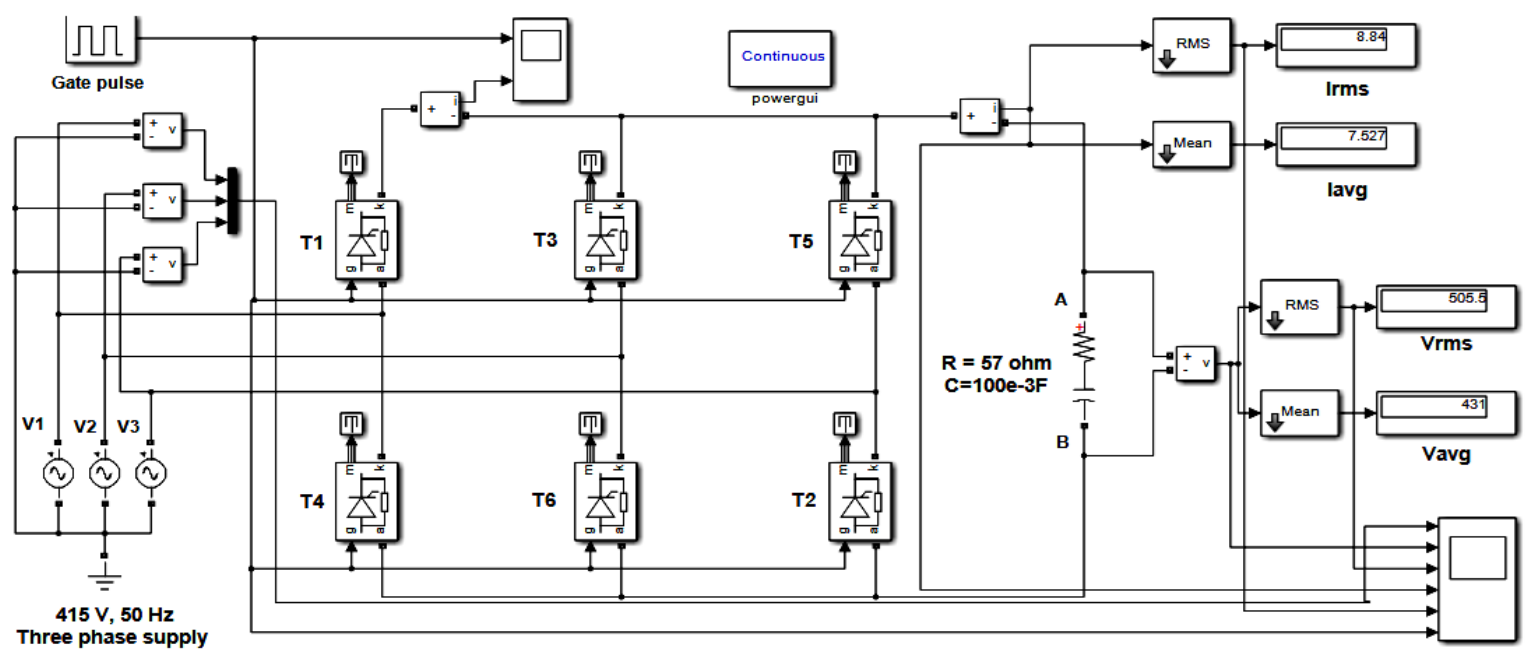

Figure 12. The simulation model of uncontrolled for FWR at load (R-C) 


\section{SIMULATION RESULTS FOR 3-PHASE RECTIFIER}

Simulation results, in this section the review had uncontrolled 3-phase rectifier for HWR, uncontrolled 3-phase rectifier for FWR, controlled 3-phase rectifier for HWR, controlled 3-phase rectifier for FWR system with different load at R, R_L \& R_C. The simulation model of uncontrolled 3-phase rectifier for HWR as show in Figure 13, the simulation model of uncontrolled 3-phase rectifier for FWR as show in Figure 14, the simulation model of controlled 3-phase rectifier for HWR as show in Figure 15 and the simulation model of controlled 3-phase rectifier for FWR as show in Figure 16. The Tables 1 and 2 include the characteristic of the parameter system, the Tables 3 to 7 include the simulation results for uncontrolled 3-phase rectifier for HWR, controlled 3-phase rectifier for HWR, uncontrolled 3-phase rectifier for FWR, and controlled 3-phase rectifier for FWR.

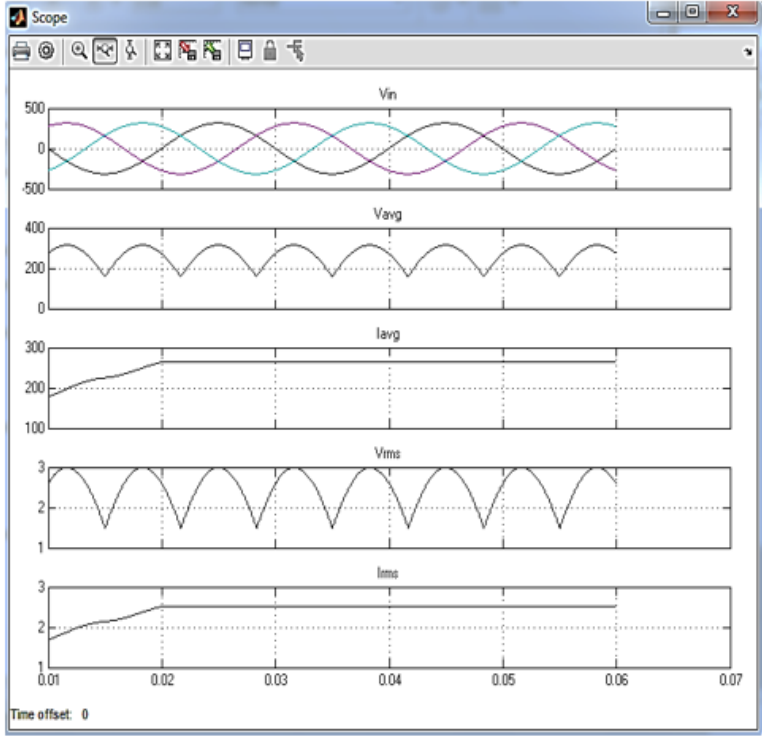

(a)

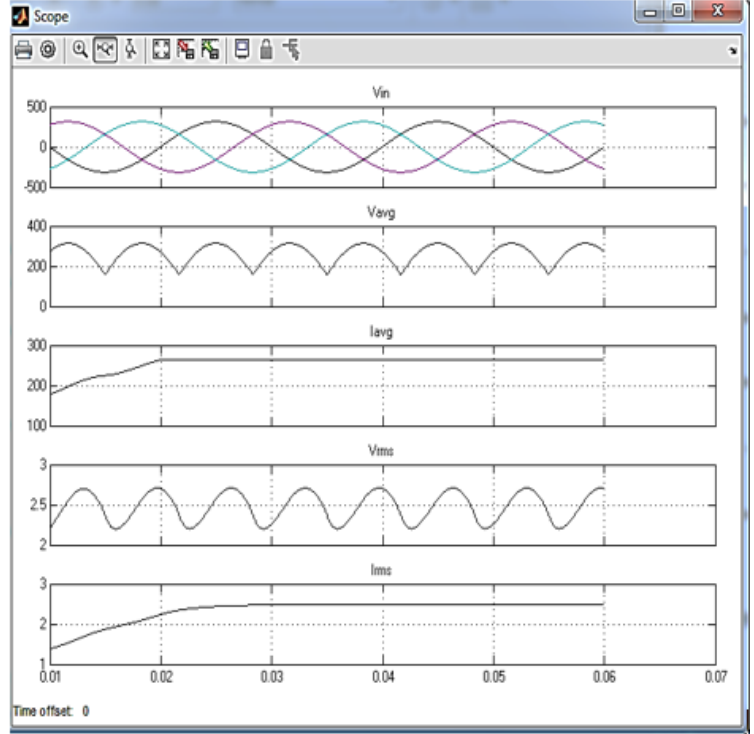

(b)

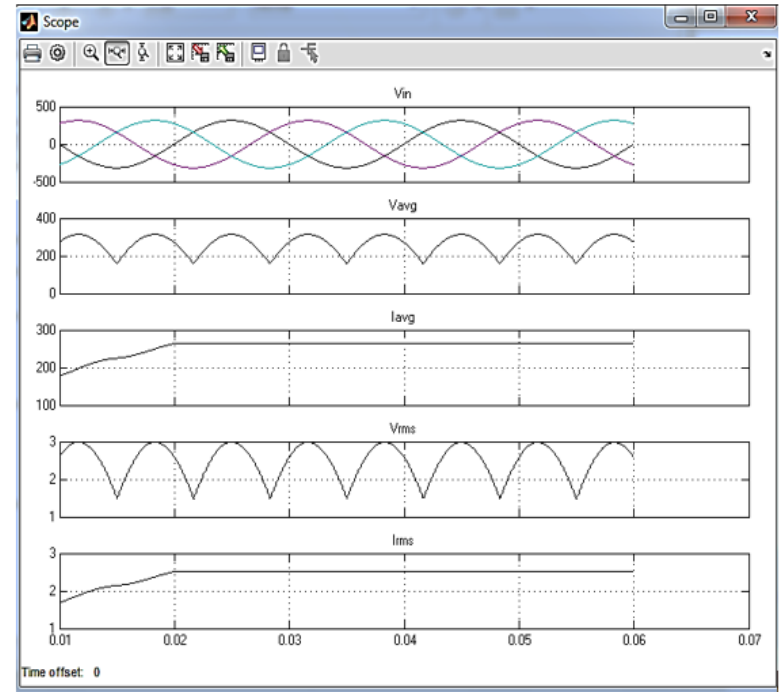

(c)

Figure 13. The simulation model of uncontrolled for HWR; (a) Uncontrolled HWR at load (R), (b) Uncontrolled HWR at load (R-L), (c) Uncontrolled HWR at load (R-C) 


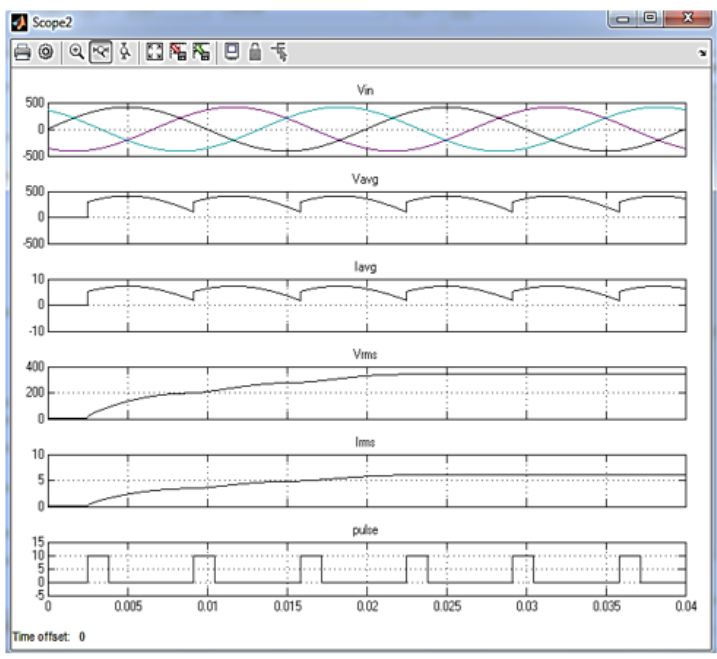

(a)

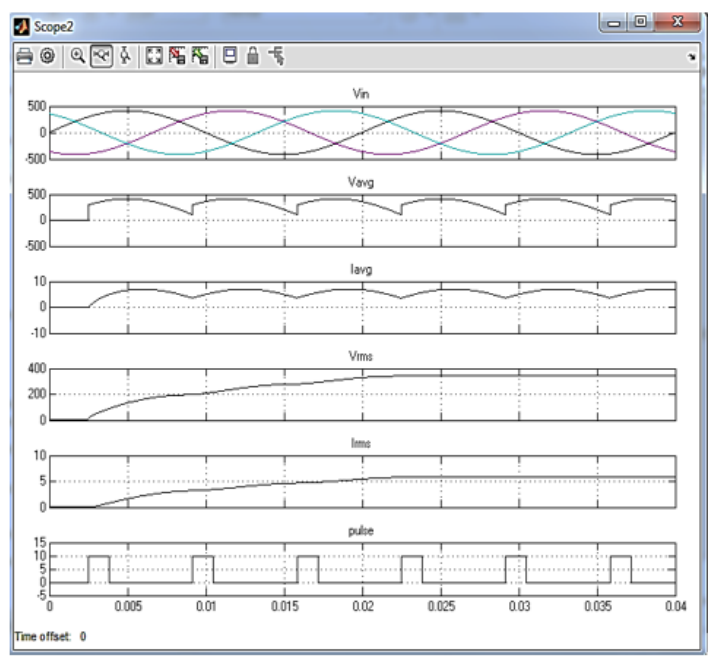

(b)

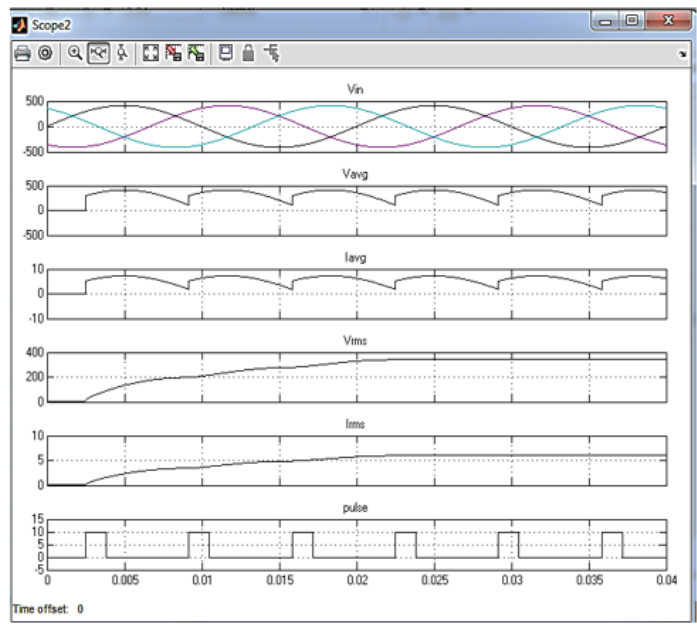

(c)

Figure 14. The simulation model of controlled for HWR; (a) Controlled HWR at load (R), (b) Controlled HWR at load (R-L), (c) Controlled HWR at load (R-C)

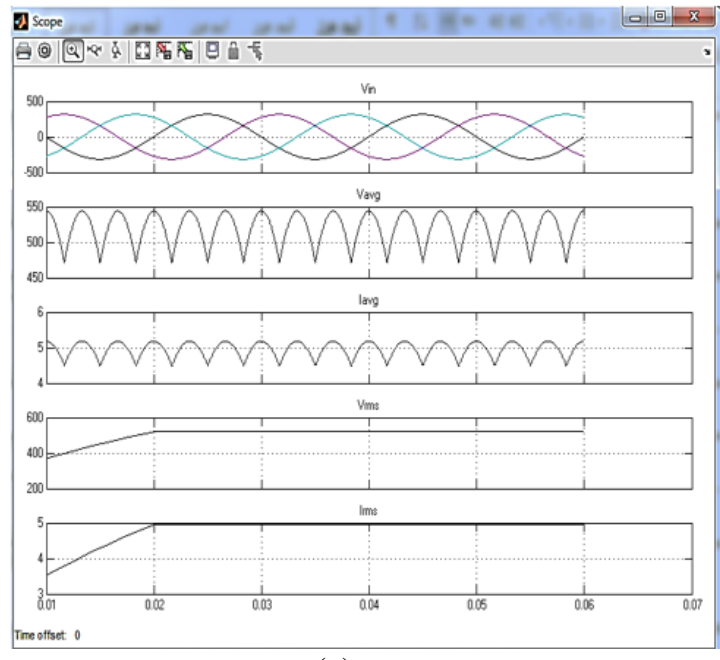

(a)

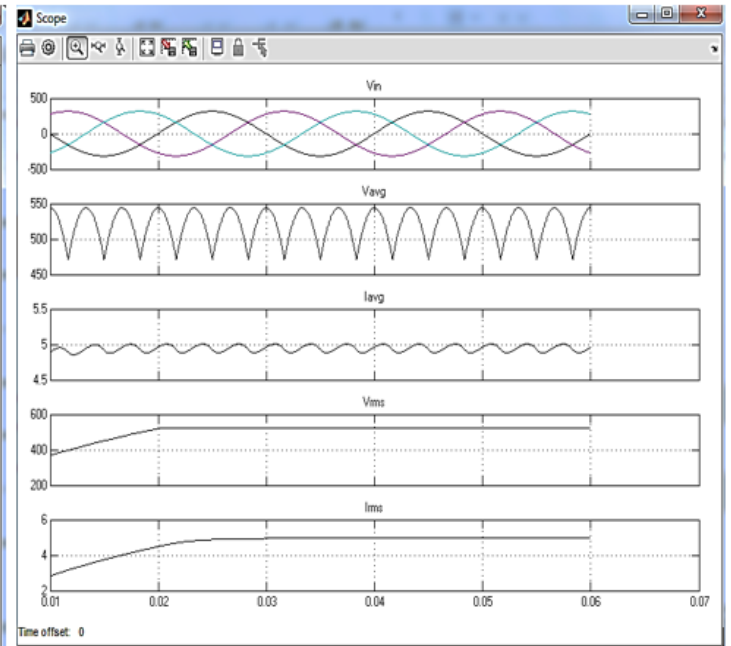

(b)

Figure 15. The simulation model of uncontrolled for FWR; (a) Uncontrolled FWR at load (R), (b) Uncontrolled FWR at load (R-L), (c) Uncontrolled FWR at load (R-C) 


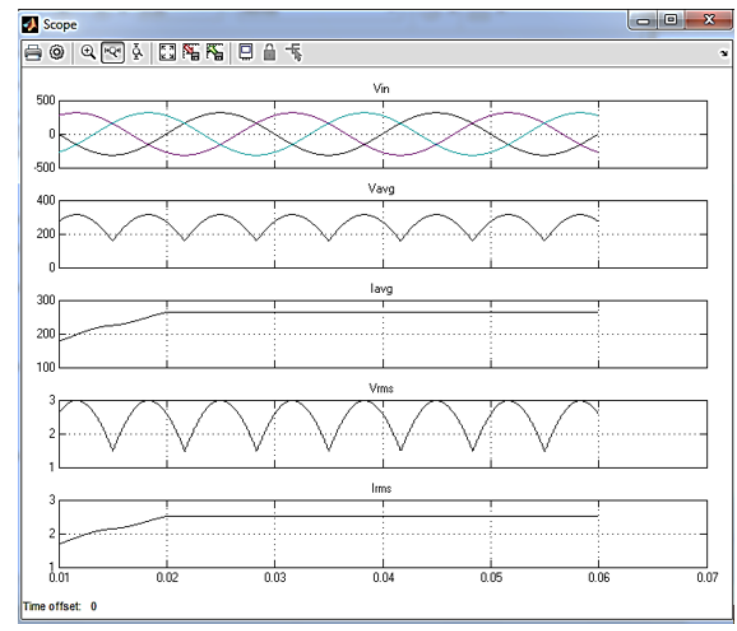

(c)

Figure 15. The simulation model of uncontrolled for FWR; (a) Uncontrolled FWR at load (R), (b) Uncontrolled FWR at load (R-L), (c) Uncontrolled FWR at load (R-C) (continue)

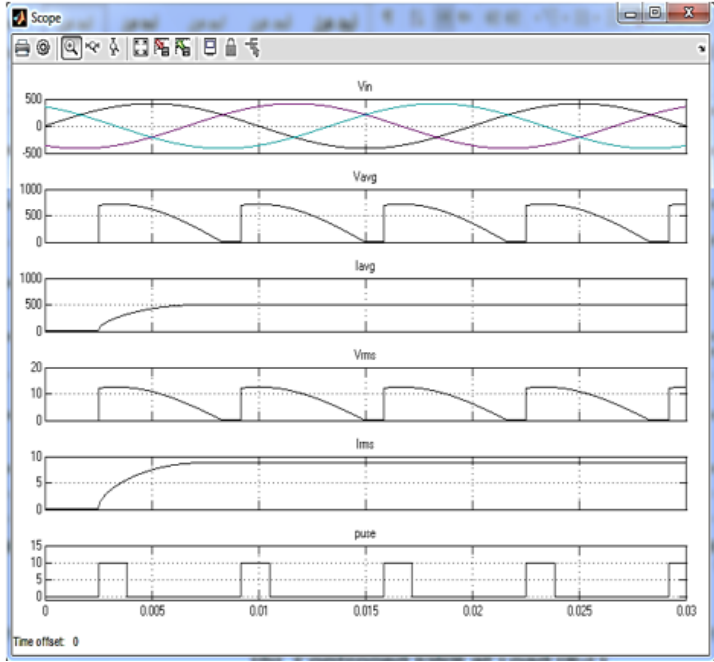

(a)

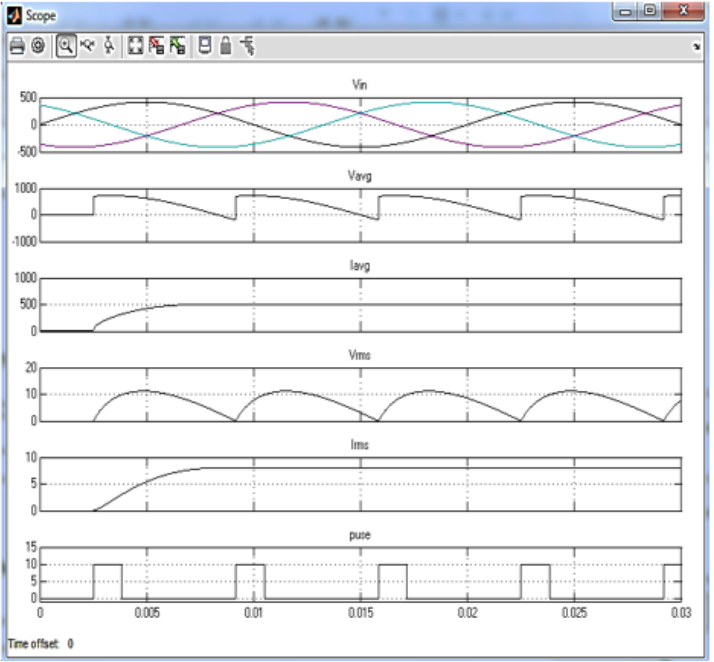

(b)

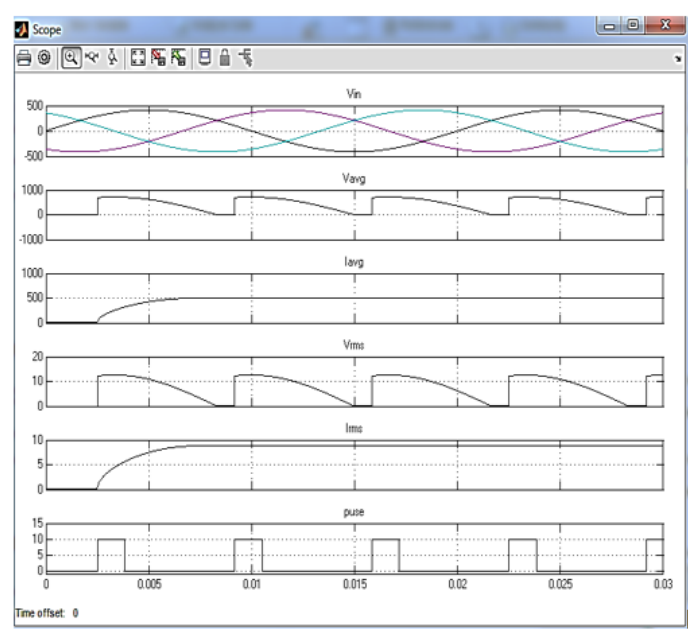

(c)

Figure 16. The simulation model of controlled for FWR; (a) Controlled FWR at load (R), (b) Controlled FWR at load (R-L), (c) Controlled FWR at load (R-C) 
Table 1. Characteristic of the parameter for 3-phase rectifier for uncontrolled system

\begin{tabular}{lc}
\hline \multicolumn{1}{c}{ Parameters } & Values \\
\hline Supply Voltage $(\mathrm{V})$ & 315 \\
Supply Frequency $(\mathrm{Hz})$ & 50 \\
$\mathrm{R}(\Omega)$ & 105 \\
$\mathrm{~L}(\mathrm{mH})$ & 250 \\
$\mathrm{C}(\mu \mathrm{F})$ & 100 \\
\hline
\end{tabular}

Table 3. Simulation results of uncontrolled 3-phase rectifier for HWR system

\begin{tabular}{ccccc}
\hline $\begin{array}{c}\text { Load } \\
\text { types }\end{array}$ & Vavg (V) & Iavg (A) & Vrms (V) & Irms (A) \\
\hline$R$ & 259.7 & 2.473 & 264 & 2.55 \\
R-L & 259.7 & 2.473 & 264 & 2.48 \\
R-C & 259.7 & 2.462 & 264 & 2.503 \\
\hline
\end{tabular}

Table 5. Simulation results of uncontrolled 3-phase rectifier for FWR system

\begin{tabular}{ccccc}
\hline $\begin{array}{l}\text { Load } \\
\text { types }\end{array}$ & Vavg (V) & Iavg (A) & Vrms (V) & Irms (A) \\
\hline R & 519.4 & 4.947 & 519.9 & 4.951 \\
R-L & 519.4 & 4.923 & 519.9 & 4.928 \\
R-C & 519.4 & 4.923 & 519.9 & 4.928 \\
\hline
\end{tabular}

Table 2. Characteristic of the parameter for 3-phase rectifier for controlled system

\begin{tabular}{lc}
\hline \multicolumn{1}{c}{ Parameters } & Values \\
\hline Supply Voltage $(\mathrm{V})$ & 415 \\
Supply Frequency $(\mathrm{Hz})$ & 50 \\
$\mathrm{R}(\Omega)$ & 57 \\
$\mathrm{~L}(\mathrm{mH})$ & 50 \\
$\mathrm{C}(\mu \mathrm{F})$ & 100 \\
\hline
\end{tabular}

Table 4. Simulation results of THPR of controlled 3-phase rectifier for HWR system

\begin{tabular}{ccccc}
\hline $\begin{array}{l}\text { Load } \\
\text { types }\end{array}$ & Vavg (V) & Iavg (A) & Vrms (V) & Irms (A) \\
\hline R & 330.7 & 5.802 & 341.2 & 5.989 \\
R-L & 330.7 & 5.802 & 341.2 & 5.898 \\
R-C & 330.7 & 5.794 & 341.2 & 5.958 \\
\hline
\end{tabular}

Table 6. Simulation results of THPR of controlled 3-phase rectifier for FWR system

\begin{tabular}{ccccc}
\hline $\begin{array}{r}\text { Load } \\
\text { types }\end{array}$ & Vavg (V) & Iavg (A) & Vrms (V) & Irms (A) \\
\hline R & 430.7 & 7.55 & 505.5 & 8.868 \\
R-L & 418.7 & 7.346 & 506.9 & 8.868 \\
R-C & 431 & 7.527 & 505.5 & 8.84 \\
\hline
\end{tabular}

Table 7. Characteristic values for 3-phase rectifier and FWR

\begin{tabular}{ccc}
\hline Characteristic type & Characteristic values for HWR & Characteristic values for FWR \\
\hline $\mathrm{P}_{\mathrm{dc}}$ (watt) & 945 & 3021.49 \\
$\mathrm{P}_{\mathrm{ac}}($ watt $)$ & 673.2 & 2574 \\
$\eta \%$ & 70.8 & 85.18 \\
$\mathrm{FF}$ & 1.016 & 1.0009 \\
$\mathrm{RF}$ & 0.1827 & 0.04 \\
\hline
\end{tabular}

\section{CONCLUSION}

The current study had carried out and included the three-phase rectifier using simulation of the three-phase rectifier by relying on circles to represent the rectifier in order to verify the different views of the researchers. In addition, to put a study in the hands of the readers, represented by how the three-phase rectifier works in different modes, which had detailed above.

\section{REFERENCES}

[1] V. Safonov and M. Dziuba, "Voltage regulation and phase quantity increase of two high-power 12-phase rectifiers," International Journal of Power Electronics and Drive Systems (IJPEDS), vol. 10, no. 3, pp. 1454-1460, Sep. 2019.

[2] S. W. Shneen, F. N. Abdullah, and D. H. Shaker, "Simulation model of single phase PWM inverter by using MATLAB/Simulink," International Journal of Power Electronics and Drive Systems (IJPEDS), vol. 12, no. 1, pp. 212-216, 2021.

[3] A. Taybi, A. Tajmouati, J. Zbitou, A. Errkik, M. Latrach, and L. El Abdellaoui, "A new design of high output voltage rectifier for rectenna system at $2.45 \mathrm{GHz}$," Indonesian Journal of Electrical Engineering and Computer Science (IJEECS), vol. 13, no. 1, pp. 226-234, 2019.

[4] S. W. Shneen, C. Mao, and D. Wang, "Advanced optimal PSO, Fuzzy and PI controller with PMSM and WTGS at $5 \mathrm{~Hz}$ side of generation and $50 \mathrm{~Hz}$ Side of Grid," International Journal of Power Electronics and Drive Systems (IJPEDS), vol. 7, no. 1, pp. 173-192, Mar. 2016.

[5] M. M. S. Khan, M. S. Arifin, M. R. T. Hossain, M. A. Kabir, A. H. Abedin, and M. A. Choudhury, "Input switched single phase buck and buck-boost AC-DC converter with improved power quality," 2012 7th International Conference on Electrical and Computer Engineering, 2012, pp. 189-192.

[6] S. W. Shneen, "Advanced Optimal for Three Phase Rectifier in Power-Electronic Systems," Indonesian Journal of Electrical Engineering and Computer Science (IJEECS), vol. 11, no. 3, pp. 821-830, 2018.

[7] R. Miyauchi, K. Tanno, and H. Tamura, "New active diode with bulk regulation transistors and its application to integrated voltage rectifier circuit," International Journal of Electrical and Computer Engineering (IJECE), vol. 9, no. 2, pp. 902 908, Apr. 2019. 
[8] S. W. Shneen, M. A. A. Hussein, J. A. Kadhum, and S. M. Ali, "Application of LFAC for electrical power transmission system: a comparative simulation study," TELKOMNIKA Telecommunication Computing Electronics and Control, vol. 17, no. 2, pp. 1055-1064, 2019.

[9] R. Grinó, E. Fossas, and D. Biel, "Sliding mode control of a full-bridge unity power factor rectifier," Nonlinear and adaptive control, Springer, Berlin, Heidelberg, pp. 139-148, 2003.

[10] S. W. Shneen, "Advanced optimal for power-electronic systems for the grid integration of energy sources," Indonesian Journal of Electrical Engineering and Computer Science (IJEECS), vol. 1, no. 3, pp. 543-555, 2016.

[11] R. Sasikala and R. Seyezhai, "Review of AC-DC power electronic converter topologies for power factor correction," International Journal of Power Electronics and Drive Systems (IJPEDS), vol. 10, no. 3, pp. 1510-1519, Sep. 2019.

[12] J. A. Kadhum, S. W. Shneen, and M. A. A. Hussein, "Utilization of DC motor-AC generator system to convert the solar direct current into 220v alternating current," International Journal of Computation and Applied Sciences, vol. 5, no. 3, pp. 391-396, Dec. 2018.

[13] N. A. Ahmed, "Modeling and simulation of ac-dc buck-boost converter fed dc motor with uniform PWM technique," Electric power systems research, vol. 73, no. 3, pp. 363-372, 2005.

[14] A. N. F. Asli and Y. C. Wong, "3.3 V DC output at-16 dBm sensitivity and 77\% PCE rectifier for RF energy harvesting," International Journal of Power Electronics and Drive Systems (IJPEDS), vol. 10, no. 3, pp. 751-758, Sep. 2019.

[15] S. W. Shneen, "BBO Tuned FLC for Three Phase Rectifier," International Research Journal of Advanced Engineering and Science, vol. 3, no. 1, pp. 262-267, 2018.

[16] N. Mohamed, T. Hamza, and G. Brahim, "Novel DTC induction machine drive improvement using controlled rectifier for DC voltage tuning," International Journal of Power Electronics and Drive Systems (IJPEDS), vol. 10, no. 3, pp. 1223-1228, 2019.

[17] R. Baharom and M. N. Seroji, "Dynamic analysis of the high-power factor three-phase AC to DC converter using current injection hybrid resonant Technique," International Journal of Power Electronics and Drive Systems (IJPEDS), vol. 10, no. 1, pp. 538-547, Mar. 2019.

[18] S. W. Shneen, "Advanced Optimal for PV system coupled with PMSM," Indonesian Journal of Electrical Engineering and Computer Science (IJEECS), vol. 1, no. 3, pp. 556-565, 2016.

[19] G. Sarowar and M. A. Hoque, "High Efficiency Single Phase Switched Capacitor AC to DC Step Down Converter," Procedia-Social and Behavioral Sciences, vol. 195, pp. 2527-2536, 2015.

[20] S. Golestan, J. M. Guerrero, and J. C. Vasquez, "Three-phase PLLs: A review of recent advances," IEEE Transactions on Power Electronics, vol. 32, no. 3, pp. 1894-1907, 2016.

[21] B. Singh, S. Gairola, B. N. Singh, A. Chandra, and K. Al-Haddad, "Multipulse AC-DC converters for improving power quality: A review," IEEE Transactions on Power Electronics, vol. 23, no. 1, pp. 260-281, 2008.

[22] R. N. Beres, X. Wang, M. Liserre, F. Blaabjerg, and C. L. Bak, "A review of passive power filters for three-phase grid-connected voltage-source converters," IEEE Journal of Emerging and Selected Topics in Power Electronics, vol. 4, no. 1, pp. 54-69, 2015.

[23] M. R. Miveh, M. F. Rahmat, A. A. Ghadimi, and M. W. Mustafa, "Control techniques for three-phase four-leg voltage source inverters in autonomous microgrids: A review," Renewable and Sustainable Energy Reviews, vol. 54, pp. 1592-1610, 2016.

[24] A. Bouafassa, L. Rahmani, and S. Mekhilef, "Design and real time implementation of single phase boost power factor correction converter," ISA transactions, vol. 55, pp. 267 274, 2015.

[25] Tyagi A. K., "MATLAB and Simulink for Engineers," Oxford University Press, 2012. 